\title{
HORROR, HUMOR E SEXO NO CINEMA DE BORDAS
}

\section{Bernadette Lyra}

Universidade Paulista

\section{Resumo}

Por suas características, modos, técnicas e procedimentos, certos filmes de ficção se enquadram naquilo que chamo de cinema de bordas. $\mathrm{O}$ cinema de bordas se faz sobre fragmentos reciclados de gêneros, subgêneros e espécies, sem que, no entanto, nenhum dentre os modelos usados se apresente determinante. Tal reciclagem genérica tem por conseqüência a ausência da novidade e da originalidade, em favor da continuidade e da repetição daquilo já anteriormente conhecido. Nesse sentido, o cinema de bordas comumente recorre a formas que materializam a ação e o sentimento, utilizados tanto por alguns gêneros cinematográficos como pela literatura popular ou literatura de massa. Este trabalho enfoca, em especial, a produção com as formas do horror, do humor e do sexo, quase sempre excluídas do discurso das instituições que consagram uma centralidade canônica. O resultado específico é uma mistura que se alimenta das bordas compostas por diferentes instâncias culturais que vai do estrato mais erudito ao mais popular e vice-versa.

Palavra-chave: gênero; filmes de bordas; cinema brasileiro. 


\section{Introdução}

No conjunto de escolhas estéticas, tecnológicas e narrativas que constituem o universo cinematográfico aparece um tipo curioso de filmes, os quais misturam recortes de gêneros, subgêneros e espécies, sem que, no entanto, qualquer um dos modelos caracterizados em tais fragmentos se apresente determinante. Nesse tipo de filme as referências genéricas são dispostas de tal forma que escapam a qualquer tentativa convencional de classificação tradicional, uma vez que não é a resolução presentificada dos gêneros que os modela, mas o modo cinematográfico com que os elementos genéricos são distribuídos.

A esse tipo particular de filmes quero chamar de cinema de bordas. Tal conceituação foi por mim desdobrada da idéia de cultura de bordas, presente no artigo "Heterônimos e cultura das bordas: Rubens Lucchetti", de Jerusa Pires Ferreira:

Com bordas quero enfatizar a exclusão do centro, aquilo que fica numa faixa de transição entre uns e outros, entre as culturas tradicionais reconhecidas como folclore e a daqueles que detém maior atualização e prestígio, uma produção que se dirige, por exemplo, a públicos populares de vários tipos, inclusive àqueles das periferias urbanas (FERREIRA, 1990:171).

Essa idéia de exclusão do centro serve para entender um cinema que não apenas se enquadra no conceito de margens, ou seja, algo excêntrico e periférico, mas também se inclui em um tipo de produção que, durante muitos anos, foi posta de lado ou foi apenas referenciada em seus relacionamentos com a produção oficializada, quer no cinema, quer na literatura ou em outros lugares. Porém, o conceito de cinema de bordas exige que não se considere, apenas, um lugar "fora" da centralidade canônica, pois ele se encontra a meio termo do centro e das extremidades, movendo-se a cada vez, em um exercício de trocas. 
Uma das vertentes possíveis no estudo desse cinema é que ele confronta a valorização da autoralidade, alinhando-se com a generalidade. ${ }^{1}$

Essas duas metodologias críticas complementam-se e contrapõem-se, uma a outra, no sentido em que a crítica de gênero tenta estabelecer um conjunto de formas cinemáticas, enquanto a crítica de autor celebra certos cineastas que trabalharam, efetivamente, no quadro dessas formas gerais (SCHATZ, 1980,p.8).

Quando falo em gênero, sei que essa noção, apesar de sua reputação assegurada na doxa da teoria e da história do cinema, pode parecer desgastada. Mas, ela se faz importante para situar este estudo, pelas seguintes razões:

Em primeiro lugar, um gênero é aqui entendido como uma forma estritamente solidária de certos sistemas de produção e difusão de filmes, além de um produto teórico desses mesmos sistemas. Assim, um gênero é algo que brota das relações existentes entre os realizadores, o público, a crítica e a indústria cinematográfica, em seus interesses e instâncias de racionalização. Em sua amplitude, a noção de gênero remete àquilo que Stephen Neale sublinhou como uma auto-reflexividade do próprio cinema:...os gêneros exibem também o cinema, cada um exibindo um aspecto particular de suas potencialidades, cada um modulando, de diferentes maneiras, instâncias de escopofilia e exibicionismo (NEALE, 1980:34).

Em segundo lugar, para este trabalho é relevante considerar que os gêneros se formaram a partir da necessidade de repetição incessante com que o sistema de produção se equilibrava desde os primeiros tempos após a invenção do cinema, diante das inovações que a indústria de filmes apresentava, em sua busca de público. A expectativa de uma estabilidade formal fazia parte dos anseios dos espectadores e, assim, explorava-se uma certa "experiência" repetida. 
Foi, portanto, com base nessa possibilidade de repetir que a indústria se organizou, não só estandartizando a manufactura de filmes, como também produzindo um público cindido (e hesitante) entre o desejo de variação e a expectativa de uma certa estabilidade formal (GRILLO, 1997:147).

Essa experiência repetida se torna genérica e alimenta o cinema. O público a ela adere, e passa a se familiarizar com formas que vão se multiplicando na ânsia de diversidade dentro da repetição.

Por esse motivo, desde os primeiros tempos, os filmes "populares" insistiam em ambiências e motivos insólitos. Daí a multiplicidade de cenários históricos ou exóticos que foram se tornando "comuns" e "reconhecidos", na tarefa de pôr os espectadores em contato com acontecimentos famosos, danças orientais, farsas e perseguições, espetáculos ilusionistas, melodramas, cenas de faroeste, entre tantos, desenvolvendo uma tipificação regular e constante que faz dos gêneros um padrão de previsibilidade dentro da diversidade.

A noção de gênero serve, assim, de base para situar as peculiaridades de filmes de borda, quando neles são mesclados os mais diversos elementos fragmentários, retomados de um déja vu cinematográfico sem que, no entanto, quaisquer deles determinem a tônica fílmica. $\mathrm{O}$ resultado específico dessa estranha mistura se alimenta das bordas compostas por diferentes instâncias culturais que vão do estrato mais erudito ao mais popular e vice-versa.

Ao demonstrar esse modo específico de organização e trocas entre fragmentos de horror, humor e sexo que compõem alguns desses filmes, tento levantar dados para uma conceituação mais exata do que estou propondo: um exame de certos filmes atípicos que constituem o cinema de bordas e uma busca do modo específico de organização desses filmes em suas formas, que incluem também domínios advindos da chamada paraliteratura ${ }^{2}$ - como romances policiais e de terror, histórias em quadrinhos, histórias pornográficas e eróticas, romances sentimentais, entre outros. 


\section{A trilogia maldita - sobrevôo}

Horror, humor e sexo sempre fizeram a parte maldita da cultura. No caso do cinema, desde sua invenção, a impressão de realidade inerente aos filmes provocou a interdição daquilo que era livre em outros meios expressivos, como a pintura e a fotografia. Essa mesma impressão de realidade do cinema exarcebou uma vigilância fundada no delírio burguês de domínio sobre a natureza e controle de "seus males", entre os quais estariam os elementos que fugiam ao controle social das normas.

Assim, tanto as monstruosidades capazes de provocar o horror quanto a nudez em seus vínculos banalmente sexuais e eróticos, quanto, ainda, o riso, em algumas das suas condições de emergência ou quando tido como prova de pouco senso, logo se viram relegados a um espaço de exceção. Tal espaço, se não era habitado por espectadores comprometidos com a moral e os bons costumes da alta cultura ou da cultura intermediária, tornava-se motivo de entretenimento para as grandes platéias populares que adotaram o cinema.

Com o triunfo arrasador do cinema sobre todos os gostos e todas as classes sociais, a idéia de entretenimento através de filmes generalizou-se, englobando a alta cultura e a midcult. Porém, apesar da democratização de público, alguns elementos em que se baseavam certos gêneros continuaram a ser preteridos, destinados a um público de gosto considerado vulgar. Pode-se afirmar que, dentro dos cânones da cultura cinematográfica, esses elementos e esses gêneros estavam destinados ao público comercial e popular, sendo, por vezes, menosprezados por críticos e estudiosos daquilo que passou a denominar-se a sétima arte. ${ }^{3}$

Os temas usuais do horror, do humor e do sexo serviam para filmes baratos e mal-feitos, beirando o escracho que, muitas vezes, eram elaborados em estúdios nas bocas do lixo da produção em todos os países e destinados à exibição em salas periféricas.

O horror, ${ }^{4}$ por exemplo, antes de entrar francamente no circuito comercial, depois do sucesso de Oexorcista (1973), de William Friedkin ${ }^{5}$, 
conheceu um ciclo fílmico iniciado pela Universal Studios, na década de 30, e se estendeu pela década de 40 com filmes produzidos por Val Lewton, na RKO, alastrando-se por toda a década de 50 com os filmes de horror em ficção científica, tal como a ficção japonesa Godzillla(1954), de Ishirô Honda. Esses filmes, depois reproduzidos amplamente pela $\mathrm{TV}$, difundiram um gosto pelo horror que se refletiu, posteriormente, no grande público disposto a ver os filmes da American International Pictures, de William Castle e da Hammer Films, com destaque para a produção de Roger Corman e George Romero. A par dessa produção, registram-se também os clássicos do horror, como aqueles feitos pelo expressionismo alemão, na Alemanha de Weimar, entre os quais $O$ gabinete de Dr. Caligári (1919), de Robert Wiene e Nosferatu (1921), de F.W. Murnau. Aliás, a figura do Conde das Trevas, Nosferatu ou Drácula sempre serviu de parâmetro para o gênero.

Quanto ao humor, rapidamente se tornou preferido pelas platéias do cinema dos primeiros tempos. Amontoados nas pequenas salas dos nickelodeons, os espectadores comiam, trocavam carícias, andavam e passeavam durante os filmes, rindo e sapateando a cada tirada humorística. A maior estrela da segunda década do cinema foi Charles Chaplin, capaz de metamorfosear-se em vagabundo irreverente que arrancava gritos e risos nas salas abafadas e lotadas. A demanda do grande público pelas comédias fez com que a produção burlesca rapidamente passasse das cenas primitivas de perseguição e das batalhas das tortas de creme às historinhas de Harrold Lloyd, Charlie Chaplin e Buster Keaton, ilustres precursores de M.Hulot, de Jacques Tati, em filmes adorados por um público ruidoso e disposto a se divertir.

Eu gostava sobretudo da redução da autoridade ao absurdo, da noção de que sexo podia ser divertido e dos insultos ousados atirados contra a pretensão, disse Mack Sennet a respeito de seus curtametragens cômicos ${ }^{6}$.

O caso do sexo é ainda mais ilustrativo, uma vez que ao grande público do cinema a censura impunha as restrições que acompanhavam o meio técnico, capaz de "representar" com crueza a carne e a 
nudez. Assim, enquanto a pintura e a fotografia podiam exibir corpos nus, em atitudes eróticas, as garotas de Viagem à Lua (1902), de Méliés, estavam condenadas a inefáveis maiôs de banho. Parceiros da nudez, desde os primeiros tempos, os filmes sobre sexo se traduziam, na maior parte das vezes, em pequenos filmes clandestinos, feitos para voyeuristas. Mais tarde, a grande onda de filmes pornôs acompanha o cinema underground ${ }^{7}$, ou cinema experimental, naquilo que ele tem de mais radical: um rompimento com o cinema bem comportado e narrativo. Filmes com cenas de sexo fetichizado são exibidos em clubes confidenciais, nas décadas de 60 e 70, antecipados por poses erotizadas da diva Bettie Page, ícone sexual dos anos 50. Com o cinema experimental, a pornografia, antes vista em sessões escusas em salas abafadas e pequenas de cinema, assume ares de cult. Prova isso o imenso sucesso de Flesh (1968) ou de Trash (1970), ambos de Paul Morrissey, com Joe Dallessandro, a primeira vedete nua homossexual do cinema.

Cada um desses três elementos - horror, humor e sexo - acaba por constituir-se em formas de pensar e atualizar um imaginário industrial, narrativo e formal, com a amplitude que caracteriza uma produção de gêneros.

\section{Reciclando o lixo com um toque erudito}

O que estou chamando de cinema de bordas não se restringe a explorar a marginalidade fílmica dos gêneros, combinando-os e recombinando-os, sobretudo, dentro dos princípios da ação e do sentimento que seduzem as platéias comuns. Por exemplo, os filmes de bordas não lidam com o horror, o humor e o sexo, cada um por sua vez. Eles incluem, em um só bloco narrativo, os elementos com que jogam em doses variáveis e com uma espécie de atualização contingente de cada elemento que, de modo isolado, não funcionaria no trânsito flutuante das bordas.

Essa mistura, no entanto, guarda uma característica básica: abole totalmente qualquer profundidade, como se fosse natural a convivência de tantos e tão díspares elementos em um só local. 
Os elementos que brotam nos fragmentos genéricos dos filmes de bordas são plenamente reconhecíveis pelo circuito dos espectadores. Isto é, tudo se passa como se as imagens visuais e sonoras do cinema de horror, de humor e de sexo estivessem à disposição para uma repetição infinita, juntada e reciclada em narrativas e situações que, na verdade, mais se parecem à costura de fragmentos de outras tantas narrativas e situações que permeiam os gêneros citados.

Ladies, gentlemen \& rapaziada em geral: queiram vocês ou não, reciclar lixo está na moda - diz, em entrevista na Internet, o realizador Peter Baiestorf, dono da produtora Canibal; Mabuse, sediada em Palmitos, no oeste catarinense.

No cinema de bordas, grande parte do lixo a ser reciclado está no próprio acervo cinematográfico, escondida em latas de filmes, mas préexiste, também, em revistas vagabundas, romances adocicados ou erótico-pornográficos, pulps $^{8}$ e mesmo velhos long-plays.

As situações retiradas da ficção paraliterária - grandes contrastes, valores muito definidos, finais já esperados - são infinitamente caras ao cinema de bordas.

Os filmes de bordas lidam com um saber variado e rebuscado que, em certos casos, mescla o melhor da literatura policial e de horror: Dorothy Sayers, G.K.Chesterton, Edgard Wallace, Edgard Allan Poe, H.P. Lovecraft, Dashiell Hammet, Nicholas Blake, Conan Doyle, Maurice Leblanc, Raymond Chandler, Agatha Christie, entre outros, são sempre benvindos a esse tipo de produção.

Observa-se, além disso, o trânsito que tais filmes de bordas mantém com a cultura erudita e com a popular, trafegando por entre vários gêneros comuns no cinema que se destinam a públicos populares, mas demonstrando um conhecimento cinéfilo apurado o qual, no mais, exercita incursões por obras em quadrinhos, peças musicais e literatura, operando nos limites de universos culturais contíguos, porém distintos. Dessa maneira, o cinema de bordas atende aos apelos de uma produção popular a partir de uma cultura erudita, o que, por sua vez, se faz em resposta direta à demanda de um tipo de público. 
Ao contrário do cinema experimental ${ }^{9}$, sempre voltado para uma expressão individual quase que puramente poética, o cinema de bordas é feito para obter uma resposta de mercado de massas.

Os procedimentos, técnicas e modos que caracterizam as formas que organizam o cinema de bordas primam pela valorização de idéias e de frases feitas, pela cumulação do sentido sensacionalista e envolvimento emocional, pelo desprezo devotado ao critério de originalidade, pela carga de descritividade, com ausência de contorno psicológico das personagens e repetição das tramas.

No Brasil e na América Latina, as conexões e passagens do antigo popular tradicional, que cabe no conceito de folclore, ao de massas, onde se concentra a idéia de trivialização cultural ${ }^{10}$, se fazem sobre a adaptação de fórmulas e clichês cinematográficos, por vezes ausentes da cultura e das coisas brasileiras, e, no entanto, absolutamente reconhecíveis no espaço do país.

As narrativas que delimitam o mundo diegético dos filmes de borda apresentam um feitio unicelular e sem complexidades, desenvolvendo-se linearmente, ao alcance do público médio. Por outro lado, a constituição narrativa que se faz sobre fórmulas exploradas ao máximo pelo cinema não poderia ser reconhecida como característica paródica. Antes, nela se consuma um ideal de refazimento genérico que demonstra um conhecimento cinéfilo por parte dos realizadores, cuidadosamente reelaborado para atingir o maior número possível de espectadores comuns.

É dessa forma que o cinema de bordas se coloca ao lado da condição de homem ordinário, do homem imaginado que atua como espectador de filmes, ao contrário de uma espécie celebrada pela idéia de um homem cultural, minoritário e imaginário. ${ }^{11}$

\section{Um exemplo de cinema de bordas no Brasil: o terrir}

Dentro do sistema de produção no qual se cruzam os eixos que determinam a natureza precária e pragmática do cinema brasileiro, 
um exemplo desse cinema de bordas é o terrir, gênero inventado por Ivan Cardoso.

Em primeiro lugar, como produz Ivan Cardoso e como se situam seus filmes, nessa constelação de formas que organizam o cinema no Brasil? $^{12}$

Ivan do Espírito Cardoso Filho (Rio de Janeiro, 1952) está envolvido naquele movimento cinematográfico que Glauber Rocha, com um certo desdém, apelidou de udigrudi. Depois que viu O Bandido da Luz Vermelha (1968), de Rogério Sganzerla, Ivan resolveu também fazer cinema. Trabalhou com Sganzerla e com Julio Bressane, engajando-se na briga contra o Cinema Novo, através da coluna Geléia Geral, sustentada por Torquato Netto, no jornal Última Hora.

Esse dado - oposição ao Cinema Novo - é decisivo para entender o cinema de bordas de Ivan que surge, exatamente, na brecha da luta contra o cinema nacional-popular da década. Como parte da marginália que configura o cinema experimental no país, a partir de 1970 Ivan Cardoso começa a produzir em super 8 a série Quotidianas Kodak, em que faz paródia dos formatos de uma sessão tradicional de cinema. Fez filmes em $16 \mathrm{~mm}$ e em $35 \mathrm{~mm}$ : documentários e cinejornais. Não se pode esquecer Nosferatu no Brasil (1971) e o filmete A múmia volta a atacar (1972), que são embriões da Múmia de Um e das Vampiras, criaturas presentes em seus dois famosos filmes de terrir realizados mais tarde. Em 1978 faz O Universo de Mojica Marins, sobre Zé do Caixão.

Em 1982, Ivan Cardoso realiza O segredo da Múmia e, em 1986, realiza seu segundo longa-metragem, As sete vampiras, dois dos melhores exemplares de filmes de borda que, ao mesmo tempo em que fazem parte da produção de uma época de embates, revelam, nas formas expressivas, uma vocação para estereótipos cinematográficos revisitados, em oposição ao que se considerava novo no cinema do Brasil.

Parte do terrir, mais especificamente, o humor, vem diretamente das formas da chanchada. A retomada da chanchada é índice claro de que Ivan Cardoso explora uma brasilidade ancorada na precariedade com que o cinema brasileiro se articulou frente aos demais cinemas ${ }^{13}$. 
A novidade cinemanovista de Glauber Rocha com sabor de filme europeu encantava os críticos da época, ávidos pelo reconhecimento internacional. Mas o público brasileiro, de fato, tem tradição de consumir filmes americanos, desde os primeiros tempos do cinema. Muita gente cresceu vendo a produção de Hollywood escoada para nós. Não é vergonha ter assistido aos musicais, aos filmes de gangsters, aos épicos de cenários de papelão de Cecil B. de Mille e aos filmes vagabundos que a orgia produtiva de Hollywood nos dava. Não é vergonha alguma ter visto isso tudo e gostado. Afinal, a despeito dos arrepios da intelectualidade, o cinema nasceu para democratizar o poleiro.

Assim, o filme OSegredo da Múmia junta recortes e retalhos do déjà $v u$ cinematográfico de horror e de sexo com gags da mais pura chancha$\mathrm{da}^{14}$. Esta múmia é, na verdade, um remake recortado de todas as múmias queHollywood expandiu para o mundo, nos filmes de horror da Universal, RKO e da inglesa Hammer Films, muitos dos quais foram exibidos na sessão Calafrio, sábado à noite na TV Record de São Paulo, em meados dos anos 70: A Maldição de Frankenstein (1957), Horror de Drácula (1958), A Górgona (1964) e Drácula, o Príncipe das Trevas (1966), e outros.

Se vamos consumir o horror, que o façamos sem rejeição, sem complexo de superioridade ou de inferioridade e sem preconceitos, parece dizer o terrir.

A múmia é nossa. Assim como os vampiros e as extravagâncias desses chupadores de sangue são nossos. Nos filmes de borda de Ivan Cardoso isso é reforçado em cenas verídicas da vida cultural brasileira que os dois filmes apresentam, tal como a curiosa seqüência retirada de um jornal cinematográfico da década de 50, em que o poeta Manoel Bandeira aparece condecorando a Miss Martha Rocha.

A cada situação em que se metem aquelas formas estranhas, o riso irrompe pelas frestas do mítico. Assim, o ambiente gótico e o Egito, que Hollywood fez questão de tratar como exóticos e ameaçadores, vão acabar assustando freqüentadores de boate e casais em um motel da Barra.

O público entendeu, pois mais de um milhão de espectadores riu, tremeu e delirou com O Segredo da Múmia e com As sete vampiras. 
Em ambos os filmes, os clichês de imagens visuais e sonoras se acumulam a cada fotograma, enquanto uma historiazinha de fácil entendimento para qualquer amante do terror desliza, enganadoramente, perfazendo os propósitos estéticos do cinema de bordas.

Ao falar na história contada nos filmes, é impossível deixar de lembrar que o roteiro de ambos é do escritor Rubens Luchetti, ele mesmo autor de histórias em quadrinhos e livros de aventuras policiais e de terror, que deixa pulsar no relato um refinado conhecimento literário e uma simpatia pelos temas paraliterários.

Eis a sinopse de O segredo da Múmia: Um cientista louco, recluso, depois de ridicularizado ao anunciar que tinha inventado o Elixir da Vida, não disse a ninguém que conseguiu restituir a vida a seu fiel seguidor, Igor. Mas o professor não está completamente só. Seu assistente, Rodolfo, é quem o acompanha na maior descoberta arqueológica do século: a revelação da tumba da múmia Runamb. Ao mesmo tempo em que o professor vai descobrindo a história da múmia ao decifrar um papiro, Runamb rapta cobaias femininas para as novas experiências do cientista. Para ele, as mulheres, em condições adversas, se transformam em feras. Nas suas escapadas noturnas, Runamb acaba encontrando a repórter de rádio Miriam, a reencarnação de Nadja, sua amada de três milênios atrás.

Eis a sinopse de As sete vampiras: Um grupo de jovens mulheres está se apresentando em um night club chamado As Sete Vampiras, em um respeitável hotel. Enquanto elas estão começando o espetáculo, os seus papéis estão para mudar quando um matador de vegetais transforma uma cientista em um vampiro. E a afinidade da vampira verdadeira com as garotas do show ameaça tornar essas vampiras de mentirinha em monstros realistas.

Entre danças voluptuosas e cenas eróticas, às quais não faltam os elementos cômicos, passeiam os monstros. A fórmula do terrir realiza, assim, a versão do cinema de bordas, entrelaçando e sobrepondo fragmentos por demais conhecidos de horror, humor e sexo, devidamente embalados por uma trilha sonora revisitada de filmes internacionais e 
compositores consagrados pelos filmes dos gêneros, aliada às composições da música popular brasileira, como é o caso do tema de As sete vampiras, performatizado na própria diegese do filme pelo cantor pop Leo Jayme.

Por fim, ao condensarem três atributos demasiadamente humanos, esses filmes não deixam de servir à desmistificação de uma cinematografia burguesa que quer considerar a prova de realidade dos filmes como autêntica, quer seja a realidade corporal dos atores, quer seja a realidade social e política.

No cinema realista e político, os personagens tentam ser eles mesmos "humanos": escondem e camuflam sua fabricação no envelope de carne e osso dos atores. Mas, as múmias e os vampiros não podem ser considerados humanos, não são de carne e osso, não demonstram humanidade na superfície da pele. Trazidos das bordas da cultura, revistos e incorporados a filmes "massivos", esses monstros, desconstruídos e desmoralizados, ao invés de tremores de medo, provocam o humor, ao exibirem a marca do modelo da humanidade às avessas.

Assim também são os monstros dos filmes de Ivan Cardoso: são feitos de impureza, resultam de uma heterogeneidade de sons e imagens já vistos no cinema, nas revistas em quadrinhos, nas ficções baratas e nas comédias rasgadas. São múmias e vampiros claramente escrachados, simulações de simulações do inumano, estereotipagem de filmes antigos que despertam um riso, às vezes maldoso, às vezes piedoso, nos espectadores.

Equando, ao terror e ao humor, o sexo éjuntado, pode-se dizer que o terrir simula aquilo que a carne humana tem de mais carne para desmistificar o desejo do cinema de se passar por algo que configura uma "humanidade".

Não adiantam tais bons sentimentos; parecem zombar esses filmes de borda. O cinema nunca será humano. Artifício e simulacro, ele está condenado ao espaço B para sempre. 


\section{Notas}

1. A vertente da autoralidade origina-se nos artigos de François Truffaud, publicados em Les cahiers du cinemas. Tais artigos rapidamente conseguiram adeptos que buscavam as marcas e o estilo de um autor dentro de um filme. Geralmente, essas marcas autorais eram atribuídas ao realizador do filme.

2. O termo paraliteratura, apesar de não estar isento de complexidade (tal como literatura) é já utilizado por estudiosos de modo corrente em lugar de "literatura popular" ou de "literatura de massa".. A paraliteratura tende para os estereótipos e está ligada a gêneros e subgêneros como o romance policial, a ficção científica, o melodrama etc.

3. O termo "sétima arte" surge em 1913, nas palavras de Ricciotto Canudo que se autodenominava " escritor italiano de cultura francesa", quando da publicação da revista Montjoie, fundada por ele, onde se interrogava sobre a especificidade e a vocação do cinema.

4. O primeiro filme considerado uma tentativa de cinema de horror da história do cinema foi The devil castle (1896), de George Méliès.

5. O Exorcista foi o primeiro filme de horror a ser indicado ao Oscarde Melhor Filme, da Acdemia de Cinema, nos EEUU.

6. Citado por Neal Gabler no livro Vida, o filme. São Paulo, Companhia das Letras, 1999 , p.52.

7. Em seu livro Introduction to the American Undergound Film, Sheldon Renan diz que "há nos filmes underground mais nudez que nos filmes comerciais, porém menos sexo". Renan, S. New York:E.P.Dutt \& Co, 1967, p.31.

8. A palavra pulp designa revistas feitas em papel barato. As histórias publicadas por elas conservam uma característica muito própria: são histórias nas quais as cenas se sobrepõem ao enredo. No Brasil, elas começam a circular a partir dos anos 20. Alguns exemplos: Detetive, X-9, Contos Magazine, Meia Noite, Suspense etc.

9. O cinema experimental remonta a um trabalho das vanguardas cinematográficas. Em 1920, o cineasta soviético Kulechov fundou um Laboratório Experimental, uma escola de inventividade e criação no cinema.Nos anos compreendidos entre 1921 e 1931, desenvolveu-se um movimento de arte, a vanguarda, que teve influ- 
ência no cinema não comercial e não representacional. No Brasil, a partir de 1967, começou a ser cultivada uma estética do experimental, no rastro do cinema Underground norte-americano, a qual produziu importantes filmes em contraposição à estética do Cinema Novo. Os quatro grandes critérios do experimental são: produção artesanal, distribuição própria, finalidade de fruição e estética mais próxima da música e da poesia. Ver: Lyra, Bernadette. A nave extraviada. São Paulo:Annablume, 1995.

10. Estou usando o termo trivialização cultural em decorrência do conceito alemão de literatura trivial (Trivialliteratur), presente em Jerusa Pires Ferreira. Op. cit. p.172.

11. A categoria de homem imaginário, desenvolvida antropologicamente por Edgard Morin, diz respeito à noção de um espectador esclarecido e conscientemente motivado, diferentemente daquela de homem ordinário no cinema, estudada por Schefer. Nesse sentido, compare: Morin, E.. Le cinéma ou l'homme imaginaire: essai d'anthropologie, Paris:Minuit, 1956, com: Schefer Jean-Louis. L’Homme ordinaire du cinema. Paris: Cahiers du Cinema;Gallimard, 1980.

12. Falar do realizador não significa um determinismo autoral, mas sim um deslizamento teórico em direção à noção de "obra", em lugar de "texto". Essa distinção se eencontra em Paul Zumthor ao formular conceitos para dar conta da especificidade da experiência medieval. Para Zumthor, o texto é um reservatório de significados, sempre à disposição dos decodificadores que saem em busca da intenção do autor. Já a obra é uma superfície composta pela superposição de formas de apresentação, nem sempre susceptíveis à interpretação. Ver Zumthor, Paul. "Body and performance", in Materialities of communication. Gumbrecht, H.U \& Pffeifer, Karl L (Org.) Stanford: Stanford University Press, 1994, p.219.

13. As chanchadas são a mais legítima produção jamais aparecida em termos de cinema no Brasil. Mas, os críticos, que tentavam desesperadamente mostrar que o Brasil tinha um cinema de Primeiro Mundo com uma estética de Terceiro, preferiram desancar as chanchadas, ao tempo em que engrandeciam o Cinema Novo, nascido das ressonâncias do neorealismo italiano e da nouvelle vague francesa.

14. O segredo da Múmia foi considerado como "quase um manifesto de cinema" pelo crítico espanhol Carlos Santos Fontella, de ABC Espetáculos, quando o filme recebeu o troféu de melhor filme no Festival de Cinema Fantástico de Madri. 
146 Bernadette Lyra

\section{Bibliografia}

FERREIRA, Jerusa Pires. "Heterônimos e cultura das bordas: Rubens Lucchetti. Revista USP, dez-jan.1990, pp.169-174

GABLER, Neal. Vida, o filme. São Paulo: Companhia das Letras, 1999.

GRILLO, João Mario. A ordem no cinema. Lisboa: Relógio d'Agua, 1997.

LYRA, Bernadette. A nave extraviada. São Paulo: Annablume, 1995.

METZ, Christian. Linguagem e cinema. São Paulo: Perspectiva, 1980.

NEALE, Steve. Genre. Londres: British Film Istitute, 1980. . "Questions of genre". Screen 31, número 1, 1990.

SHATZ, Thomas. Hollywood genres: formulas, filmmaking and the studio system. Filadélfia: Temple University Press, 1980.

ZANELLA, Cristiano. O cinema nacional tem salvação e vou provar isso com meus filmes bagaceira. Entrevista com Peter Baiestorf. www. nao-til.com.br .2004. 